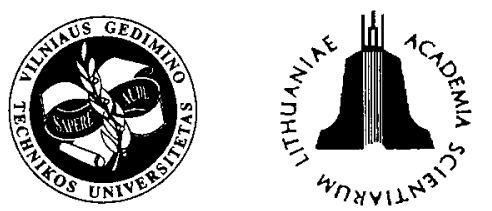

JOURNAL OF CIVIL ENGINEERING AND MANAGEMENT

http:/www.vtu.lt/english/editions

2002, Vol VIII, No 4, 286-290

\title{
APPLICATION OF TRANSPARENT INSULATION MATERIALS TO BUILDINGS HEATING IN PASSIVE SOLAR SYSTEMS
}

\author{
Halina Koczyk, Andrzej Górka, Małgorzata Basińska \\ Division of Heating, Air Conditioning and Air Protection, Poznan University of Technologv, \\ ul. Piotrowo 3a, 60-965 Poznani. Poland. E-mail: Malgorzata.Basinska@put.poznan.p
}

Received 20 Feb 2001; accepted 12 Sept 2002

\begin{abstract}
The aim of this paper is to present a numerical model, based on the finite difference method and able to describe the heat transfer in a room with indirect passive solar system in form of transparent insulation material (TIM) wall. Results of numerical calculations of thermal fields in TIM wall, in room with passive solar system, under climatic conditions of typical meteorological year for Poznan, are presented. Also the estimation of energy savings for selected rooms with TIM wall is given.

Construction of a numerical model of building includes calculation of distribution of temperatures in all walls forming the enclosure, composition of system of energy balance equations for nodes representative of rooms and its solution. In numerical calculations of the thermal states of rooms with transparent walls, an analysis of respective components of thermal balance there has been conducted, in conjunction with required radiator heating power of automated heating installation - coacting with passive solar systems (PSS), as well as variability of $\eta$ in the comparative year including months from September to April.
\end{abstract}

Keywords: transparent insulation material, heat transfer in a building, efficiency of passive solar system, average comparative year, finite difference method, numerical model.

\section{Introduction}

Many solutions have been proposed to save energy for heating in passive solar systems (PSS). A solar wall provides a possibility to improve and to optimise many different solar systems [1-5].

We can use different types of solar walls. Function of the passive solar wall is to enable solar energy collection in order to reduce energy consumption for standard heating installations. This wall stores heat during the sunny period and releases it with a time lag, which depends on the characteristics of the wall type [2].

We can use solar walls for renovation of the building facade. In this way we can protect the old wall and reduce the coefficient of thermal transmittance ( $U$ value), but the solar wall can also give a heat gain. In some articles we can find criteria of choosing different types of solar walls [3]. Some modifications have been made to improve their efficiency.

One of the latest passive systems is a wall consisting of transparent insulation material (TIM) and construction part covered with an absorbing surface.

The transparent material is characterised by a high solar transmittance and low infrared losses. Transparent materials were introduced to improve the solar transmittance and thermal resistance of the wall system. Heat losses are compensated by heat gains and solar collector wall acts as a heat source for the room.

Therefore quite generally TIMs are used for [1]:

- low ambient temperature or high operating temperatures,

- low irradiation level,

- long operating time for storage collectors or passive storage walls.

Next application were solar collectors to prevent top heat losses during the night and thus eliminate the necessity of extra insulating cover after sunset. Few workers have attempted to work on transparent insulation in solar water heaters [6]. Other types of TIM are in use in the industry (capillary glasses and aerogels). Transparent insulation gives interesting possibilities for architectural integration, concerning both opaque walls and glazing, for both heating and daylighting applications [3, 7].

Modelling thermal behaviour of buildings with transparent insulation has been the object of many studies [8-12].

This paper presents a numerical model of a building with the PSS, in particular, direct or indirect. The aim of presented calculations was to assess energy efficiency of PSS, in form of transparent collector-accumulator walls, for conditions of climate of Poznan. The calculations were made for climatic conditions of com- 
parative year for Poznan city, computed using the "average year" method based on environmental data spanning ten years [13].

\section{Problem formulation}

The problem under consideration is heat transfer in a building with PSS in form of TIM wall.

The mathematical model of a building constitutes the systems of partial differential equations, which describe heat conduction in material layers, the equations of heat balance for the rooms of building.

System of model equations is completed by boundary and initial conditions systems.

The following main assumptions have been made:

- walls forming the enclosure are discussed as multilayered plane walls;

- air temperature is assumed to be equal in a room space;

- heat conduction in material layers is considered as one-dimensional disregarding corners, thermal bridges and window framing;

- heat transfer on internal surfaces of the walls takes place with constant heat convection coefficients;

- heat convection coefficients on external surfaces of the walls are wind speed functions;

- transmittance coefficient for glazing depends on the Sun's position;

- climatic factors (external air temperature and solar radiation) are given in annual hourly courses.

The aim of this paper is to present a numerical model based on the finite difference method [10]. The model is able to calculate the thermal behaviour of a building with indirect and direct PSS.

The presented model can be also used for analysing thermal balance components for buildings equipped with a PSS, conventional heating system and energy efficiency.

\section{Accepted numerical model of a building with PSS}

To solve a model of a building with PSS in form of TIM wall implicit finite difference method has been used. Schematic model of a fragment of a building enclosure with PSS based on quantization method is shown in Fig 1.

The building is considered as a set of rooms characterised by different appropriation and exploitation, connected by walls of different construction.

Construction of a numerical model of building includes calculation of distribution of temperatures in all walls forming the enclosure, composition of system of energy balance equations for nodes representing rooms and its solution. Numerical model of individual room composed of $n$ walls, in which a structure of each wall is represented by $m_{j}$ nodes, constitutes a system of energy balance equations.

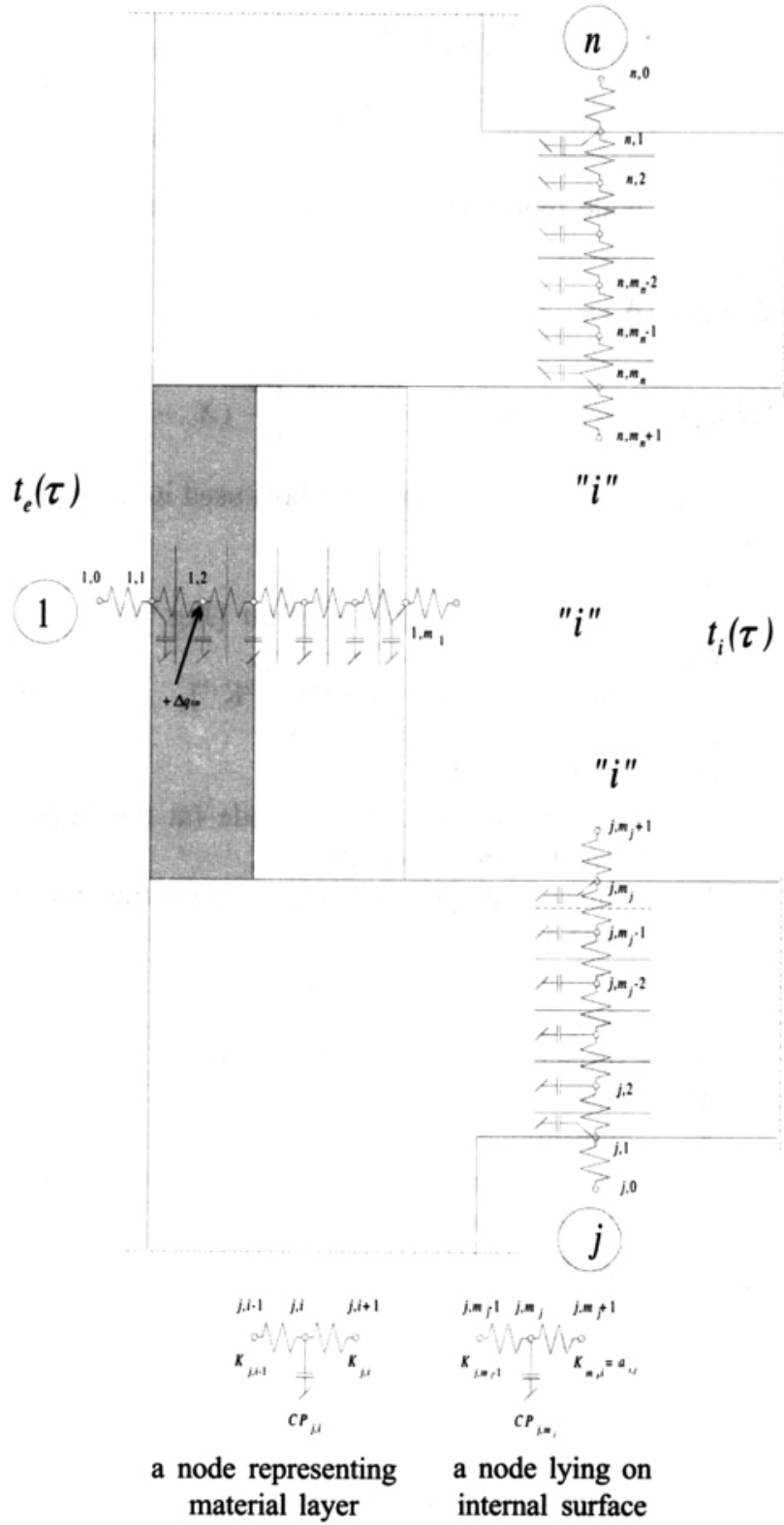

Fig 1. Diagram of a building enclosure with PSS

With reference to Fig 1, energy balance equations for characteristic nodes are as follows:

- for a node representative of material layer

$$
\begin{array}{r}
K_{j, i-1}\left(X_{j, i-1}-X_{j, i}\right)+K_{j, i}\left(X_{j, i+1}-X_{j, i}\right)= \\
\frac{C P_{j, i}}{\Delta \tau}\left(X_{j, i}-T_{j, i}\right) ;
\end{array}
$$

- for a node lying on absorptive surface of accumulating layer in transparently insulated wall

$$
\begin{array}{r}
K_{1, i-1}\left(X_{1, i-1}-X_{1, i}\right)+K_{1, i}\left(X_{1, i+1}-X_{1, i}\right)+ \\
a \cdot \tau_{T I M}\left(I_{r}+I_{b}\right)={ }_{\Delta \tau}^{C P_{1, i}}\left(X_{1, i}-T_{1, i}\right) ;
\end{array}
$$

- for a node lying on internal surface of walls that form enclosure of a room 


$$
\begin{array}{r}
K_{j, m_{j}-1}\left(X_{j, m_{j}-1}-X_{j, m_{j}}\right)+K_{j, m_{j}}\left(X_{i}-X_{j, m_{j}}\right)= \\
C P_{j, m_{j}}\left(X_{j, m_{j}}-T_{j, m_{j}}\right) \\
\Delta \tau
\end{array}
$$

- for a node representative of air in the room

$$
\begin{aligned}
& \sum_{j=1}^{j=n} K_{j, m_{j}}\left(X_{j, m_{j}-1}-X_{j, m_{j}}\right) A_{i, j}+Q_{H}(\tau)+ \\
& \Delta Q_{P S S}(\tau)+n(\tau){ }_{c_{p}} \rho V\left(X_{e}-X_{i}\right)=\frac{{ }_{c_{p}} \rho V}{\Delta \tau}\left(X_{i}-T_{i}\right) .
\end{aligned}
$$

List of the most important symbols used in the equations:

A - internal area $\left[\mathrm{m}^{2}\right]$,

c - specific heat capacity of air $\left[\mathrm{Jkg}^{-1} \mathrm{~K}^{-1}\right]$,

$C P$ - thermal capacity $\left[\mathrm{Jm}^{-3} \mathrm{~K}^{-1}\right]$,

$K$ - thermal conductivity $\left[\mathrm{Wm}^{-2} \mathrm{~K}^{-1}\right]$,

$n$ - ventilation rate [s],

$Q \quad$ - heat flow [W],

$T$ - actual temperature in a node (at the beginning of time interval) $\left[{ }^{\circ} \mathrm{C}\right]$,

$X \quad$ - forecast temperature in a node (at the end of time interval) $\left[{ }^{\circ} \mathrm{C}\right]$,

$V \quad-$ ventilated volume $\left[\mathrm{m}^{3}\right]$,

$\rho \quad-$ density $\left[\mathrm{kgm}^{-3}\right]$,

$\alpha$ - surface film conductance $\left[\mathrm{Wm}^{-2} \mathrm{~K}^{-1}\right]$,

$\Delta \tau$ - interval of the time [s],

$\tau_{\alpha}$ - transmittance of solar radiation,

$\tau_{T I M}$ - transmittance of solar irradiation for transparent insulation material.

List of subscripts:

$P S S$ - passive solar system,

e - external,

$H$ - heating,

$i$ - number of a node, internal,

$j \quad-$ number of a wall,

$m$ - number of material layers.

The system of equations of energy balances ought to be solved for each wall in every step of time. The system of equations which binds all the equations systems for walls forming the enclosure of an individual room is system of equations of thermal balance for nodes representative of air in single rooms.

Additional heat flow related to direct passive solar system $\Delta Q_{P S S}(\tau)$ resulting from heat transfer equation in window subsystem:

$$
\Delta \dot{Q}_{P S S}(\tau)=\sum \dot{q}_{s i}(\tau) A_{o i}(\tau \alpha)_{i},
$$

where: $q_{s i}(\tau)$ - heat flow density of solar radiation on vertical plane of given orientation;

$A_{o i}$ - surface of windows of given orientation, subjected to solar radiation;

$(\tau \alpha)_{i}$ - generalised transmittance (through glazing) coefficient.

Internal heat sources efficiency $\Delta \mathrm{q}_{\mathrm{TIM}}$ results from radiation absorption in elementary layer of transparent material. Heat properties and radiational-optical properties of transparent material, namely equivalent coefficients of heat conductivity and solar radiation transmittance coefficients, were taken depending on the kind of transparent structure according to [14].

Standard generalised transmittance of solar radiation through glazing is given as formula:

$$
\tau_{\alpha}=\alpha_{1} \alpha_{2} \alpha_{3}\left(\tau_{\alpha}\right)_{s}
$$

where: $\left(\tau_{\alpha \alpha}\right)_{s}$ - depends on the Sun's position.

Transmittances of solar radiation for transparent insulation $\tau_{T I M}$ are given by Wittwer [14].

The above procedure gives temperature distributions in all elements forming the building in every time step of simulation period.

\section{Aim and scope of work}

The aim of presented calculations was to assess energy efficiency of PSS, in form of transparent collector-accumulator walls, for conditions of climate of Poznan. An analysis of heat balance of selected rooms has been conducted for three different construction models of walls, of varying thickness and transparent materials properties.

Three material-construction solutions were discussed:

- transparent wall number 1 consisting of following layers: transparent "honeycomb" structure $0,04 \mathrm{~m}$, full brick $0,25 \mathrm{~m}$, plaster $0,015 \mathrm{~m}$;

substitute heat transfer coefficient $\mathrm{U}=1,1 \mathrm{Wm}^{-2} \mathrm{~K}^{-1}$;

- transparent wall number 2 consisting of following layers: transparent polystyrene $0,108 \mathrm{~m}$, normal concrete with stone aggregate $0,2 \mathrm{~m}$, cement-lime plaster $0,015 \mathrm{~m}$;

substitute heat transfer coefficient $\mathrm{U}=0,78 \mathrm{Wm}^{-2} \mathrm{~K}^{-1}$

- transparent wall number 3 consisting of following layers: polycarbonate foam $0,02 \mathrm{~m}$, full brick $0,25 \mathrm{~m}$, cement-lime plaster $0.015 \mathrm{~m}$;

substitute heat transfer coefficient $\mathrm{U}=1,28 \mathrm{Wm}^{-2} \mathrm{~K}^{-1}$.

In every discussed case the room was equipped with transparent collector-accumulator wall, with a single window (single wooden window with two layers of glass) of given surface, resulting from the requirements of day lighting; and a conventional heat source.

Numerical solution has, in every case, led to establishing the required heat power course for heating cooperating with PSS ensuring full solar energy usage for purposes of heating a building in a process of automated heating regulation.

The calculations were made for climatic conditions of comparative year for Poznan city, computed using the "average year" method based on environmental data spanning ten years [13]. Basic data relating to external temperature for average comparative year (ACY) for Poznan are shown in Fig 2.

Accepted courses of direct radiation falling on surface perpendicular to sunbeams are presented in Fig 3 


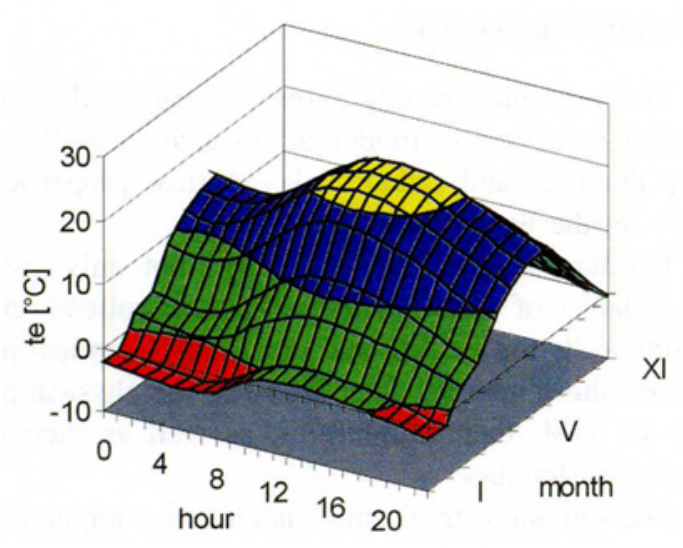

Fig 2. Accepted courses of external temperature in ACY of Poznan

and courses of diffuse radiation are presented in Fig 4.

All calculations were computed for selected rooms classified as typical in one-family buildings. Construction models of room lining barriers, apart from collector or collector-accumulator elements of PSS, were inferred from typical project solutions for architecture of insulating property given according to data from the early 90 's, or increased insulating property (close to the standards for world energy-efficient architecture). Rooms of sur-

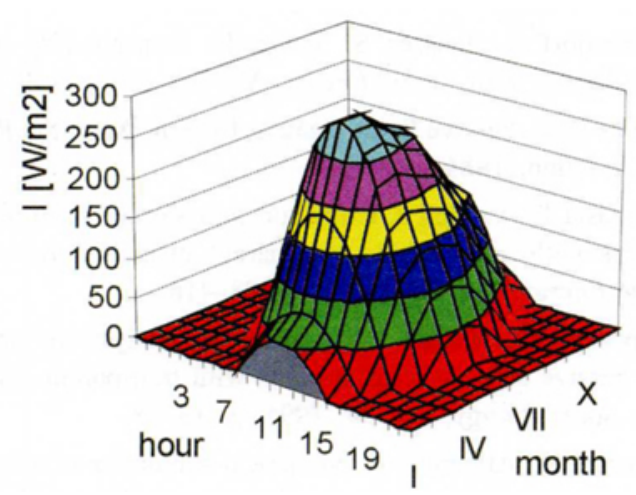

Fig 3. Accepted courses of direct radiation for Poznan

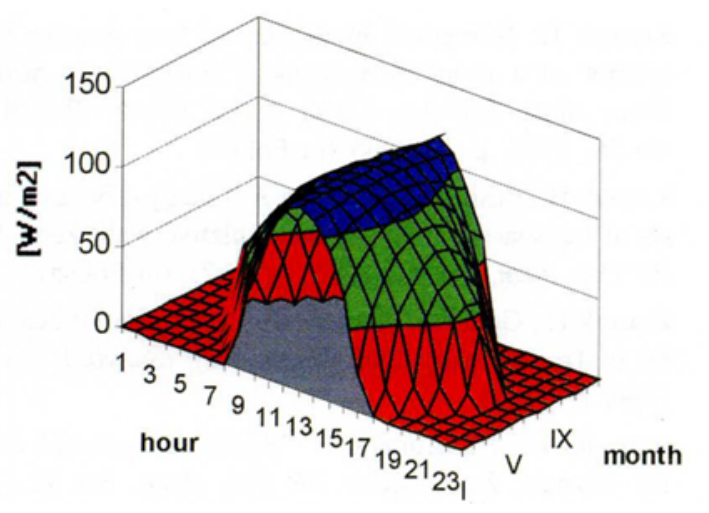

Fig 4. Accepted courses of diffuse radiation for Poznan face $16 \mathrm{~m}^{2}$, and height $2,5 \mathrm{~m}$ - of following room-encasing barrier construction model, were considered.

For the indirect gain system, with transparent collector-accumulator walls calculations have been conducted for six room units:

- normal insulating property: middle and corner units of the first and second floors;

- increased insulating property: corner units of the first and second floors.

\section{Assessment of energy efficiency of collector-accu- mulator transparent walls}

The point of reference, in the assessment of energy efficiency of collector-accumulator transparent walls, should be the actual heat usage of a room. Actual heat usage of a room may only be assessed by monitoring the energy usage, coupled with monitoring the external environmental factors (ie climate).

By numerical analyses only an approximate value of energy usage for heating purposes might be deduced. As a point of reference in the assessment of energy efficiency, the following measures can be taken: heat loss of room lining coupled with heat demand for heating the infiltrating air (actual or nominal) or the heating power of convective radiator working together with PSS.

In the presented analysis, there have been proposed the following criterion for assessing the energetic efficiency of collector-accumulator transparent walls coefficient actual heat gain, as referenced to insulation, in relation to the actual heat usage of a room:

$$
\eta_{r}=\frac{\dot{Q}_{P S S}}{\dot{Q}_{\text {used }}}
$$

where:

$\dot{Q}_{P S S}$ - heating power "net" of the PSS element (taking into account effect of gains and losses)

$\dot{Q}_{\text {used }}$ - actual energy usage for heating the room purposes, dependent on $\dot{Q}_{P S S}$ and radiator heating power $\dot{Q}_{H}$ given in formula:

$$
\begin{array}{ll}
\dot{Q}_{u s e d}=\dot{Q}_{H} & \begin{array}{c}
\text { when } \quad \dot{Q}_{P S S} \leq 0 \\
\text { (heat losses prevail); }
\end{array} \\
\dot{Q}_{\text {used }}=\dot{Q}_{H}+\dot{Q}_{P S S} & \begin{array}{l}
\text { when } \dot{Q}_{P S S}>0 \\
\text { (heat gains prevail) }
\end{array}
\end{array}
$$

In numerical calculations of the thermal states of rooms with transparent walls, there has been conducted an analysis of respective components of thermal balance, in conjunction with required radiator heating power of automated heating installation - coacting with PSS, as well as variability of $\eta$ in the comparative year including months from September to April.

On Figs 5 and 6 the results of calculations of $\eta_{r}$ have been presented, for preselected rooms and analysed 
construction models of transparent walls. Fig 5 concerns variability of $\eta_{\mathrm{r}}$ in the heating season, in corner rooms of the first and second floor, of normal insulating property and on Fig 5 - in corner rooms of the first and second floor, of increased insulating property.

As concerns the efficiency of PSS, it has been proven that correct assumption concerning the thickness of isolation layer is quite important. For the collectoraccumulator transparent walls, advantageous values assessment coefficients $\eta_{r}$, for both construction models of transparent walls 1 and 2 have been obtained by the calculations. So concerning, for example, the transparent wall $1 \eta_{r}$ coefficients are 0,02 for corner room of a structure with average or increased insulating property.

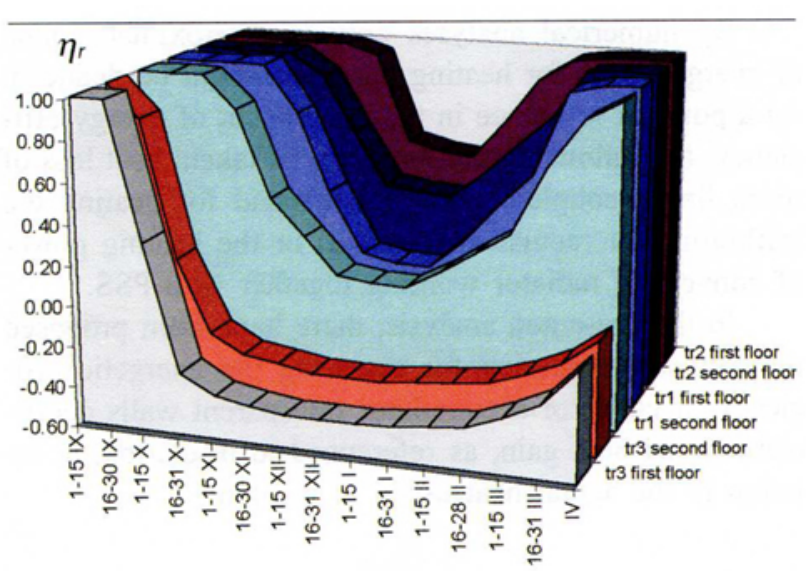

Fig 5. Variability of $\eta_{r}$, in the heating season, in corner rooms of the first and second floor, of normal insulating property

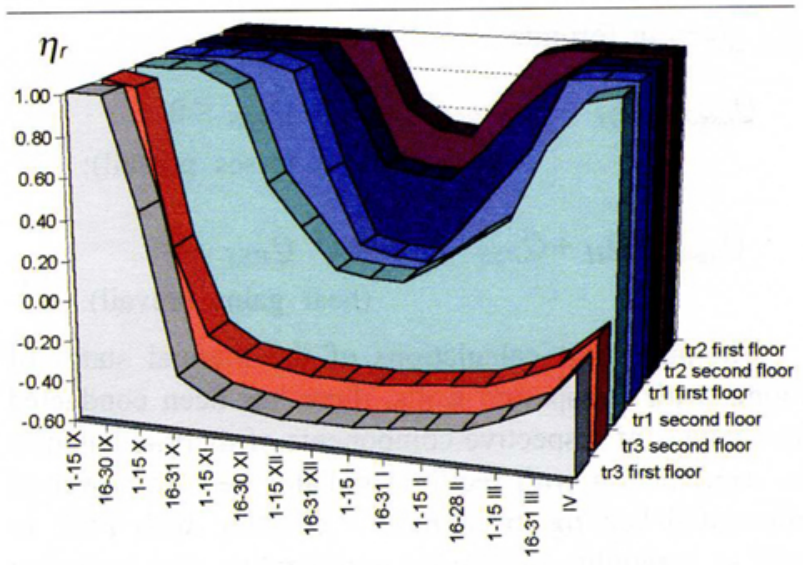

Fig 6. Variability of $\eta_{r}$, in the heating season, in corner rooms of the first and second floor, of increased insulating property

\section{Concluding remarks}

The presented results show a strong influence of assumed construction model of transparent wall, especially the heat and radiational - optical properties of TIM - on the heat balance of rooms.

Further research should concern not only the energy balance of rooms with transparent collector-accumulator walls for set heat and radiational - optical properties of those materials, but above all the physical properties of TIM, their durabilities, as well as their construction techniques.

Showed algorithms and elaborated computer program can be applied to other investigations of thermal behaviour of heated buildings with PSS, among other things, ventilation efficiency of Trombe wall and longterm heat requirements for building with PSS.

\section{References}

1. Platzer W., Karlsson B., Ojanen T. Optimisation of geometric media for solar application. IEA Solar heating and cooling programme. 1996.

2. Zalewski L., Lassue S., Duthoit B., Butez M. Study of solar walls - validating a simulation model. Building and Environment, Vol 37, 2002, p. 109-121.

3. Dalenback J. Solar energy in building renovation. Energy and Buildings, Vol 24, 1996, p. 29-50.

4. Rockendorf G., Janssen S., Felten H. Transparently insulated hybrid wall. Solar Energy, Vol 58, 1996, p. 33-38.

5. Lebens R.M. Passive Solar Heating Design. Appl. Sc. Publ. Ltd, London, 1984.

6. Chaurasia P., Twidell J. Collector cum storage solar water heaters with and without transparent insulation material. Solar Energy, Vol 70, 2001, p. 403-416.

7. Peuporties B., Michel J. Comparative analysis of active and passive solar heating systems with transparent insulation. Solar Energy, Vol 54, 1995, p. 13-18.

8. Ramadan H., Athienitis A. Numerical simulation of a building with one transparently insulated wall. Renewable Energy, Vol 15, 1998, p. 387-390.

9. Athienitis A., Ramadan H. Numerical model of a building with transparent insulation. Solar Energy, Vol 67, 1999, p. 101-109.

10. Koczyk H. Numerical modelling of heat transfer in the interior of a room in analysis of unstationary heatings. Prace Nauk. Inst. Inz. Chem. i Urz. Ciepln. Pol. Wrocl., No 50, 1987, p. 229-235 (in Polish).

11. Koczyk H., Basińska M., Górka A. Energy efficiency analysis of transparent collector accumulative wall. Zesz. Nauk. PP Pol. Pozn, No 43, 1995, p. 59-71 (in Polish).

12. Koczyk H., Górka A. Numerical investigation of heat transfer in Trombe wall. Civil Engineering (Statyba), No 2(6), 1996, p. 73-79.

13. Antoniewicz B., Koczyk H. Models of external climate for Poznan. Zesz. Nauk. PP Pol. Pozn. No 32, 1990, p. 285-295 (in Polish).

14. Wittwer V. Transparent insulation materials. New Perspectives for Solar Energy Application, 1988. 